\title{
Disaster preparedness and response: a challenge for hospitals in earthquake-prone countries
}

\author{
Susan M. Smith* \\ Department of Applied Health Sciences, \\ Indiana University, \\ Bloomington, IN 47405, USA \\ Email: smithsu@indiana.edu \\ *Corresponding author
}

\section{June Gorski and Hari Chandra Vennelakanti}

University of Tennessee,

Knoxville, TN 37996, USA

\begin{abstract}
An effective and immediate response from hospital personnel is critical to meet the needs of affected populations at the time of an earthquake disaster. Hospitals need to develop, practise and continuously update an effective disaster/emergency medical response plan. Communities and impacted regions cannot depend on immediate medical and humanitarian aid from other outside sources to meet medical care needs during the first three to five days following an earthquake. How hospitals in earthquake-prone countries such as India, Pakistan and Haiti can improve their medical response is discussed. This discussion of methods to improve effective disaster response of the medical and public health community include a description of important efforts to enhance hospital accreditation, increase personnel training, and use a response capacity checklist.
\end{abstract}

Keywords: hospitals; disaster preparedness; earthquakes; emergency response.

Reference to this paper should be made as follows: Smith, S.M., Gorski, J. and Vennelakanti, H.C. (XXXX) 'Disaster preparedness and response: a challenge for hospitals in earthquake-prone countries', Int. J. Emergency Management, Vol. $\mathrm{x}$, No. $\mathrm{x}, \mathrm{pp} . \mathrm{xxx}-\mathrm{xxx}$.

Biographical notes: Susan M. Smith, EdD, MSPH, is the Director of the Heartland OSHA Training Institute \& Education Center and an Associate Professor of Safety and Health Education in the Department of Applied Health Sciences at Indiana University Bloomington. She teaches graduate courses in emergency and crisis management, emergency planning, threat assessment and unintentional injury prevention. Her research areas include emergency preparedness, evacuation practices and disaster planning for special populations.

June Gorski, DrPH, CHES, is a Professor of Public Health and Health Education at the University of Tennessee. She has been honoured by the University for both teaching and public service. She has taught professional development courses for health educators, international health, death and dying and bereavement, women's health and programme planning. Her research interests include health practices of women and youth and strategies to reduce unintentional injuries. 


\section{S.M. Smith, J. Gorski and H.C. Vennelakanti}

Hari Chandra Vennelakanti recently received MS degree in Safety degree with concentrations in both Emergency Management and Safety Management from the University of Tennessee, Knoxville, Tennessee.

\section{Introduction}

The Asia-Pacific region where India and Pakistan are located has experienced $60 \%$ of the world's natural disasters. India is located within the Himalayan belt, which is one of the most active seismic regions of the world. The Sikkim earthquake of 14 February 2006, which impacted the southern districts of Sikkim, India, represented the third most significant earthquake this region had experienced in the past 50 years. A review of the record of disasters worldwide found that India had the highest number of individuals affected by disasters in the world between the years 1966 and 1990, reporting 1552 million individuals. India reported 216 separate disasters between the years 1966 and 1990. When India was compared with other developing countries for this same period, it ranked second for experiencing the most disasters in the world. India ranked ninth out of the top 20 countries, with 91,400 deaths during 1966-1990. More recently, India reported experiencing 18 disasters during 2007 (International Disaster Database, n.d.; Noji, 1997).

However, the two earthquakes with the largest magnitude in the first quarter of 2010 occurred in the regions of South and North America. The first earthquake struck 15 miles from Port-Au-Prince in Haiti on 12 January 2010 and caused catastrophic damage to a majority of medical facilities, housing and road systems near the epicentre. The damage to this small country was exacerbated by the fact that as an island nation most of the soils were composed of sand, and building codes prior to the earthquake were minimal. A very strong second earthquake occurred in Chile, South America, on 27 February 2010 with a magnitude of 8.8 and was one of the largest recorded earthquakes to hit this region. This earthquake destroyed much of the road system in the region near the town of Chilean, delaying the delivery of food and medical supplies as well as leaving death and destruction of homes in its wake.

Since a high rate of natural disasters is projected to continue and/or increase across the world, particularly in areas with dense populations, all healthcare facilities need to create, practise and implement efficient and effective disaster response planning to provide an adequate medical disaster response (Noji, 1997; Dara et al., 2005; Kaushik et al., 2006). For example, in India, healthcare is primarily a state function with the central government involved mainly in policy and specific disease-control programmes. While there are formal private sector medical care facilities and informal sector practitioners, the level of care varies. Regulatory problems for India include no database of private providers, no ability to enforce regulations and a lack of resources for regulatory bodies (Merson et al., 2006). Thus, attention to disaster preparedness in India needs to include both public and private sector hospitals.

In the South America region, Peru fared relatively well after the 2007 Ica earthquake. Response plans were a significant factor in providing services immediately after the earthquake. The plans helped the staff to continue providing services and care for the affected population. Despite considerable earthquake damage, patients with HIV and TB were receiving care. A total of $78 \%$ of the facilities in the four provinces most affected 


\section{Disaster preparedness and response}

(Cañete, Chincla, Ica and Pisco) reported providing medical care within 48 hours after the earthquake. Public facilities were more likely to continue operations than were private facilities. Of importance were facilities with an emergency response plan that were able to provide services and arrange referrals when care could not be received at a particular facility (Chapin et al., 2009).

Chapin et al. (2009) stated the 2005 Pakistan earthquake (7.6 magnitude) left only $32 \%$ of the health facilities functional. In the Marmara Region of Turkey in 1999 the damage from a 7.4 magnitude earthquake was devastating to $26 \%$ of the hospitals, destruction to 28 health centres and damage 20 health centres. The 6.6 magnitude earthquake in Bam, Iran, during 2003 was cited as destroying nearly all health facilities in the surrounding area and without an adequate healthcare infrastructure since approximately half of the local health staff were dead or missing (Chapin et al., 2009).

An unprecedented public health response was critical when an earthquake struck Haiti on 12 January 2010. International assistance was needed for a population who were already suffering from a lack of access to healthcare, poverty and high rates of unemployment. The reports shared with the US news sources indicated: 222,517 deaths, 310,928 injured, 105,000 homes destroyed, 208,000 homes damaged and 1.2 million people displaced (CNN, 30 March 2010). The most common medical problems were traumatic injuries from the earthquake, such as lower limb and arm amputations, and exacerbations of chronic disease due to lack of access to healthcare (APHA, March 2010).

\section{Thesis}

Continuous improvement of medical responses by healthcare facilities and government agencies across the world is critical to reduce the impact of natural disasters on citizens. This paper will focus on hospitals and the need for hospitals to respond rapidly to a disaster; however, 'hospitals' are used throughout the paper in a general way to reflect any healthcare facility that would be in a position to provide medical care during and after a disaster. In describing disasters, the authors elected to focus on earthquakes given the frequency of occurrence, and the high mortality and morbidity rates reported following these natural disasters.

\section{Applications}

'Hospitals have always been an important link in the chain of disaster response and are assuming even more importance as advanced pre-hospital care capabilities lead to improved survival-to-hospital rate' (Dara et al., 2005, p.S3). Individuals in disaster medicine reported the need to improve the ability of healthcare facilities to rapidly respond to a disaster and for professionals to coordinate activities of multiple agencies. This report also urged hospitals in India to incorporate 'surge' capacity in their planning. A relatively small number of injured persons can create a surge and overwhelm the normal capacity of a local healthcare facility even if the facility is not damaged by the earthquake. When healthcare facilities plan for an effective medical response following a natural disaster such as an earthquake, it is important to be familiar with the magnitude 


\section{S.M. Smith, J. Gorski and H.C. Vennelakanti}

and types of injuries and illnesses most likely to occur during an earthquake or other natural disaster. A study by Jain et al. in 2003 found casualties after the 2001 earthquake in Gujarat, India, to be 250,000 injured people. The preparedness and response capacity of the healthcare facilities were evaluated by Dr. Rannveig Bremer following the January 2001 earthquake in Gujarat, India. Bremer's (2003) findings indicated "substantial deficiencies in the existing healthcare system available in this region added to the severity of the disaster" (p.370). Bremer's analysis found efficient coordination was lacking, and policies on the delivery of disaster relief had not been developed.

This earthquake of 2001 in Gujarat, India, demonstrated the ability of a natural disaster with rapid onset to shake the 'lifeline and health system of about two-thirds of the population of India's Gujarat state' (Nanda, 2008, p.1). An assessment of the impact of this natural disaster found the 'earthquake claimed more women and children as victims and resulted in 14,000 deaths and thousands injured, maimed, or rendered homeless and destitute' (Nanda, 2008, p.1). Most foreign field hospitals did not arrive in Gujarat until five to seven days after the earthquake occurred. This predicable lag in international support generated a huge surge locally in medical demand for the first week. Only one of the two major hospitals still functioned without critical structural damage after the earthquake. Also a temporary hospital was established by private and government doctors from nearby areas and tent field hospitals were provided by the Indian army. Completing an assessment of medical disaster response following the earthquake, Bremer (2003) and Nanda (2008) recommended that effective disaster planning and coordination between facilities and organisations would have improved the Gujarat earthquake post-disaster medical response.

A further assessment in 2002 completed by Roy et al. of the same Gujarat earthquake supported the importance of local doctors from secondary and primary health centres in the buffer region to provide ambulances and limited supplies. While emphasising the importance of local medical staff in response since 'outside medical assistance arrived too late for immediate care' (Roy et al., 2002, p.193). Investigators emphasised the lack of formal orthopaedic care. Since crush injuries are reported as a major cause of death from those injured following an earthquake, providing adequate and prompt care for 'crush' injuries is critical in the prevention of deaths (Roy et al., 2002). Roy and his colleagues found that the early discharge of those injured and the resistance of patients to be transferred to tertiary hospitals far away from the patient's relatives contributed to higher post-operative complications from earthquake injuries (Roy et al., 2002).

Speed in providing effective emergency medical services and healthcare within the first 24 hours following a disaster is critical to minimise deaths and permanent disability following a natural disaster such as an earthquake. The heavy demand placed on local hospital services for immediate disaster medical care demonstrates the need for every hospital to be prepared to handle an unpredicted surge in workload. Hospitals must be prepared prior to a natural disaster occurring to have an adequate medical response when the disaster strikes. Following the Gujarat disaster the Indian government took action to enhance national- and state-level responses addressed by creating a National Response Plan. A national disaster planning effort created the National Disaster Management Authority that requires each state in India to establish a Disaster Management Authority and district disaster management committees. Also, the Ministry of Health in India initiated a process to assess existing gaps in the management of disasters and issued policy guidelines to improve the disaster management system. To improve disaster 


\title{
Disaster preparedness and response
}

response, the health sector of the national Indian government initiated support for mobile hospitals, specialised search and rescue medical teams, and building capacity for the management of mass casualties (Kaur, 2006). In India, the primary responsibility for disaster response is the state level which is similar to the USA (Dara et al., 2005; Kaur, 2006; Mehta, 2006).

However, a report authored by USAID in 2006 reported individual states within India experiencing limited resources still lacked state-level plans. The shortcomings focused on delayed response, lack of resources to implement a mass evacuation, failure to keep an essential inventory of medicines and life-saving equipment in 'ready stock' and a lack of coordination among government departments. This same USAID publication (2005) documented prior case studies of disasters. This review found operating procedures that were to provide relief following a disaster were to be 'non-existent' in some cases. An additional study by Metri (2006) discussed methods to improve disaster mitigation and management and reported community awareness and disaster management effort to be 'poorly coordinated'.

Most recently, the earthquake in Haiti challenged the medical care professionals to provide life-saving practices in order to save lives and to reduce suffering. One account of the challenges faced by an emergency medical relief team from Stanford University Hospital and Columbia University Medical Center in the USA who worked under the auspices of the International Medical Corps, a non-profit organisation, described the following scene in Haiti. In countries with few strong building codes the damage following an earthquake to the population and healthcare facilities is usually greater.

\begin{abstract}
"Approximately 800 victims were within the hospital compound, most of them outdoors. A damaged building was filled with the patients deemed in greatest need of emergency surgery. Hundreds of patients awaited evaluation and treatment. An internal medicine ward was packed with patients with crush and other severe soft-tissue injuries, amputations, open and infected fractures, compartment syndromes, hemorrhagic shock, and other conditions threatening to life and limb. In a central wooded area outside, the ground was barely visible for the suffering people, many of whom had distorted limbs, maggot-infested wounds, deforming facial injuries, skull fractures, and spinal cord injuries. A single operating room with a few tables was staffed by overworked surgeons who amputated limbs and débrided infected tissue" (Auerbach et al., 2010, p.e32).
\end{abstract}

In addition to the existing hospitals, field hospitals were built to treat patients. However, there was no functioning authority coordinating the distribution of available medical resources. Medical personnel had to decide which patients to accept and which patients would be denied treatment.

"Patients with infected open fractures were admitted, were operated on, and underwent débridement as needed. They received perioperative intravenous antibiotics and were discharged the next morning. The patients received a fullcourse supply of oral antibiotics and a discharge letter and were asked to come for follow-up within the next several days. At the entrance to the hospital, we had a waiting area that accommodated approximately 20 patients, most with open fractures. These were patients whom we had already triaged and decided to admit, and they were now awaiting hospitalization. With the discharge of each patient, a new patient could be hospitalized. Our policy of very early discharge permitted us to treat more than 100 patients per day in a facility with 72 beds" (Merin et al., 2010, p.e38). 


\section{S.M. Smith, J. Gorski and H.C. Vennelakanti}

Hospitals are a vital resource during disasters caused by earthquakes. However, every critical disaster resource affecting healthcare is needed during an emergency. Urgent medical needs and basic survival supplies are necessary during the first response efforts. While coordinating response activities can be daunting, the challenges are further hampered when offices operated by government, international agencies and non-profit organisations are destroyed or so damaged that the daily operations cease. The next section of the paper offers insight into developing response capacity and social capital before an earthquake occurs.

\section{Findings}

In this section, attention will be given to measures that would be beneficial to hospitals in responding to disasters. However, hospitals are valued resources in a community and medical care personnel need support from other service and public health workers to adequately address human needs during a disaster. Based on a collective response to disasters, the authors have selected to focus on literature describing the medical and public health response, accreditation standards for hospitals, training needs and the use of check lists to determine response capacity.

In a programme promoted by the US Department of Health and Human Services, priorities were cited for increasing the preparedness level of hospital disaster response. The priorities were improving the surge capacity of a facility, providing supplies and for hospitals to provide related education and training. These were the three key components of emergency preparedness for hospitals. The ability to 'surge' is dependent on pre-planning for the use of the medical facilities' own resources such as staff and supplies and the ability of the facility to quickly link with resources outside of its own structure to increase the communities ability to locate, identify and triage patients (Knotts et al., 2006). In the USA, as in most earthquake-prone countries, the surge capacity of local hospitals to respond to an emergency has greatly diminished in the past 20 years. A survey conducted by the American Hospital Association in 2007 reported local hospitals were at $100 \%$ staff capacity during non-disaster periods; therefore, when disaster strikes additional capacity is not available (Kaji et al., 2007).

When an earthquake strikes near a facility that is already at or exceeds patient capacity during a non-disaster time period, this facility may not have the ability to respond rapidly. The facility may also need to supplement its medical and support staff. Hospital personnel could be directly impacted by the earthquake causing the staff or their family members to be casualties. Once patients are triaged it is also critical for the facility to have a plan in place to facilitate moving individuals out of the immediate earthquake region to a less damaged medical facility. While the top priorities of disaster rescue teams are to rescue and provide immediate care for physical trauma, prior planning to allow the establishment of transportation corridors to move evacuees can also be essential to the long-term survival of those injured in an earthquake (Knotts et al., 2006; Gautschi et al., 2008).

One practical strategy identified by Knotts et al. (2006) used to increase the speed of finding and initiating the treatment of earthquake victims in 2006 was the use of the Simple Triage and Rapid Treatment (START). The programme incorporates the use of triage tags in combination with the use of glow sticks to help transport teams relocate 


\section{Disaster preparedness and response}

victims. This combination system was found to not only increase the speed of transport of a victim to a medical facility following a disaster but to also reduce errors during the transport and immediate care of victims.

The impact from inadequate disaster planning by healthcare facilities and government disproportionately affects those individuals who are the most vulnerable following a disaster which includes children and the elderly. Kaur's (2006) work based on evaluating the responses of the local healthcare facilities, state, regional and national governments to past natural disasters found that the following factors negatively impact the effectiveness of disaster response:

- Poor coordination at the local level and the lack of an early warning system

- Very slow response times

- Limited number of trained and dedicated clinicians

- Lack of a systematic search and rescue system and equipment

- Poor community empowerment and participation

For example, in India these factors had contributed to the poor response from disaster relief and healthcare facilities according to professionals associated with the Ministry of Health and Family Welfare of India. The national institutional framework for health policy and coordination was created by the Indian government to strengthen the ability of the state and national governments of India to support an effective relief and emergency medical response to disaster. This framework did not require each healthcare facility to create, practise and maintain an up-to-date disaster medical plan. Although the federal government established a national framework plan, specific actions are needed by each healthcare facility in India to adopt and implement disaster medical plans. Thus, improvement could be evident in the medical response capacity of each healthcare facility (Kaur, 2006).

\subsection{Accreditation standards}

National accreditation systems have been used successfully to provide needed impetus for healthcare facilities to maintain and practise up-to-date disaster/emergency plans. To assist medical care personnel with critical disaster situations, it is helpful to know that accreditation standards provide guidance to those responsible for maintaining accreditation standards for hospitals. Knowledge of the availability and quality of trauma-care systems in different regions of a country is critical for those planning to respond to the increase in injuries following a natural disaster. Unintentional injuries remain a major public health problem in many earthquake-prone countries. For example, an assessment by Joshipura et al. (2003) reported, "the Government of India has failed to recognize it (injury) as a priority" (p.686). It was also reported in 2003 that trauma centre access in India varies by state, region, wealth of a community and population even in non-disaster periods. Since 'crush' injuries are one of the primary health problems following an earthquake, a medical disaster response plan must address the increased demand for trauma care and surgery during a disaster surge (Joshipura et al., 2003).

In addition to increasing access for potential victims to trauma medical services, it is important for healthcare facilities to address the need for maintaining quality at each trauma centre. The effort to accomplish this consistency in quality should be addressed 


\section{S.M. Smith, J. Gorski and H.C. Vennelakanti}

through the development of a national accrediting system for healthcare facilities. A study in India found that 'no mechanism for accreditation of trauma centres and professionals exists' (Joshipura et al., 2003, p.686). This situation exists in many of the most earthquake-prone underdeveloped or developing countries of the world. In many developed countries, including the USA, hospitals are required to have an emergency/ disaster response plan as a part of the requirements for accreditation. In the USA, this accreditation process is operated by the Joint Commission on Accreditation of Healthcare Organizations (JCAHO). However, as late as 2006 like many other countries, India had 'no statutory body to regulate and accredit', hospitals (Mehta, 2006, p.89). For example, in May 2008 it was reported by Sharma et al. (2008) that only a few hospitals in India have sought and received accreditation for their services. This reported group included five hospitals and several medical institutes who had received accreditation from the Joint Commission International (JCI). The international organisation JCI is affiliated with the leading accrediting agency JCAHO which is focused on healthcare quality in the USA. Sharma et al. (2008) reported that Delhi-based Escorts Hospital was accredited by the British Standards Institute.

An accredited programme contributes to a viable disaster medical response. In 2008, one group of analysts provided the following assessment: 'the attitude of hospitals toward quality certification [accreditation] is very cold' (Cherukara and Manalel, 2008, p.375). This statement was made at a May 2008 professional conference concerning medical care quality and the need for improvement in India. Thus, the Quality Council of India which 'operates a national accreditation structure and obtains international recognition for its accreditation schemes' remains challenged as in many rapidly developing countries to reach a goal of having a majority of healthcare facilities in India nationally accredited (Sharma et al., 2008, p.467).

\subsection{Checklist to record response capacity}

While accreditation may be too involved for smaller hospitals to undertake, a disaster capacity assessment may be accomplished through the use of a checklist. In countries without a strong hospital accrediting system, a checklist or a disaster training programme has been implemented. The checklist allows for the uniform documentation of a health facility's disaster response capacity. While checklist criteria have been generated by agencies, the following ten evaluation criteria developed and used for hospitals in Nepal provide an overview of the main areas that should be addressed. The criteria provided here were generated by the World Health Organization's Emergency and Humanitarian Action Team (Emergency and Humanitarian Action Newsletter, 2006). The criteria categories used to evaluate a healthcare facility's capacity to provide medical care services following a disaster included:

- Current disaster planning strategy

- Bed capacity

- Surgical capacity

- Blood transfusion resources

- Supplies of medicines and equipment

- Staff availability 


\section{Disaster preparedness and response}

- $\quad$ Staff training

- Communication facilities and clarity of message

- Transport availability

- Disease surveillance and control.

When a survey tool was designed using the criteria, the tool was reviewed and field tested by an epidemiologist from the London School of Hygiene and Tropical Medicine. The Emergency and Humanitarian Action Team chose to implement the data collection project in Nepal. The project was designed to provide a national perspective on the healthcare system's disaster medical response plan in Nepal. A similar project could be used to gather information on the medical response capacity of hospitals in many earthquake-prone countries (Emergency and Humanitarian Action Newsletter, 2006).

\subsection{Disaster response training for healthcare workers}

Checklists can focus on many aspects essential to medical care response; however, the actual persons delivering care are critical responders. These individuals ensure injuries are reduced and lives are saved. It is difficult to access the quality of the response using only a checklist. Following the 2004 disaster response to the tsunami in Sri Lanka, an assessment of post-disaster healthcare services by Wickramasinghe et al. (2007) identified the need to provide targeted training to prepare healthcare workers for future medical disaster responses. These authors identified 'the development and implementation of a disaster management course for healthcare workers' (p.765) as a priority to improve medical disaster response. Disaster medicine physicians promote disaster education and training as one of their primary professional roles and can effectively advocate to ensure disaster preparedness training is implemented. This training must include a focus on communicating effectively not only with the patient but also with family members and first responders (Dara et al., 2005).

The International Strategy for Disaster Reduction, The World Health Organization and the World Bank partnered with governments, organisations and individuals worldwide to raise awareness through the '2008-2009 World Disaster Reduction Campaign'. A critical component of the campaign was supporting the need for 'preparing and training the health workforce to act in emergency situations' (United Nations, 2009a; United Nations, 2009b). The experience of young medical responders from the 8 October 2005 earthquake that struck Pakistan illustrated the lack of preparation by final-year medical students to provide the medical response to a disaster. '... we were entirely unprepared for the task of treating casualties of the Kashmir earthquake - we had not had any disaster management training or exposure to real-time emergency situations' (Sabri and Qayyum, 2006, p.1452). These medical students were quickly confronted with challenges associated with search and rescue, unsupervised emergency care for patients, personal emotions from viewing the rubble and human suffering, prioritising medical attention, managing children's injuries and the obstacles associated with gender issues (Sabri and Qayyum, 2006). Ofrin and Salunke (2006) have cited the importance of using training and regular drills to build capacity for medical disaster response. These challenges and others need to be included in the curricula that are used to train medical personnel and hospital staff to respond in a disaster. Additionally, any training effort for medical and hospital personnel needs to incorporate effective communication skills. 


\section{S.M. Smith, J. Gorski and H.C. Vennelakanti}

\section{Discussion}

There is a need for hospital and other healthcare facilities to create an effective response capacity for earthquake disasters. This can be accomplished through preparing and practising disaster plans, participation in accreditation processes and by conducting training for hospital personnel. Local medical personnel who typically practise outside the hospital need to practise disaster response in collaboration with their hospital counterparts. These drills should be conducted using available healthcare facilities and by using alternate locations as practice sites. This second action is necessary because medical building structures can be rendered unsafe or destroyed by an earthquake.

The earthquake challenges facing India and other countries discussed in this paper are not unique to only these regions. Rather, the global community is positioned to share best practices with nations affected by earthquakes. India is making progress in disaster response; however, issues pertaining to hospital accreditation, training curricula on disaster preparedness, qualified personnel and adequate resources, including health expenditures for disasters and assessment of response capabilities, are universal needs. Governments are in a positioned to provide leadership but it takes collaboration among public and private healthcare sectors to protect and care for populations affected by natural disasters. Emergency preparedness is a universal global need. No standard framework has been provided for community members or researchers interested in comparing the capacity of their healthcare facilities to function following an earthquake event with others except the very complex system of overall ongoing review conducted under the JCI. One reason a standard framework has not been proposed is that as in most situations assessing emergency response capacity must be somewhat site and facility specific to be effective. However, the checklist developed in Nepal and outlined in this paper can serve as one example of a tool that can be used to help assess specific capacities such as bed capacity across a country or region.

\section{References}

American Public Health Association (APHA) (2010, March) Global Public Health Community Responses to Devastation in Haiti, The Nation's Health, p.9.

Auerbach, P.S., Norris, R.L., Menon, A.S., Brown, I.P., Kuah, S., Schwieger, J., Kinyon, J., Helderman, T.N. and Lawry, L. (2010) 'Civil-Military Collaboration in the Initial Medical Response to the Earthquake in Haiti', The New England Journal of Medicine, Vol. 362, No. 10, p.e32.

Bremer, R. (2003) 'Policy development in disaster preparedness and management: lessons learned from the January 2001 earthquake in Gujarat, India', Prehospital and Disaster Medicine, Vol. 18, No. 4, pp.370-382.

Chapin, E., Daniels, A., Elias, R., Aspilcueta, D. and Doocy, S. (2009) 'Impact of the 2007 Ica earthquake on health facilities and health service provision in Southern Peru', Prehospital and Disaster Medicine, Vol. 24, No. 4, pp.326-332.

Cherukara, J.M. and Manalel, J. (2008) 'Medical tourism in Kerala: challenges and scope', Proceedings of the Conference on Tourism in India Challenges Ahead, 15-17 May 2008, IIML, pp.369-379.

CNN Program (2010, 30 March) Television Broadcast, CNN, USA.

Dara, S.I., Ashton, R.W., Farmer, J.C. and Carlton, P.K. (2005) 'Worldwide disaster medical response: an historical perspective', Critical Care Medicine, Vol. 33, No. 1 (suppl), pp.2-6. 


\section{Disaster preparedness and response}

Emergency and Humanitarian Action Newsletter (2006) 'Health facility preparedness in Nepal', Issue VIII, p.4. Available online at: www.nep.searo.who.int/LinkFiles/Publications_EHA NL-Issue08-Sep06.pdf (accessed on 17 October 2010).

Gautschi, O.P., Cadosch, D., Rajan, G. and Zellweger, R. (2008, March-April) 'Earthquakes and trauma: review of triage and injury-specific, immediate care', Prehospital and Disaster Medicine, Vol. 23, No. 2, pp.195-201.

International Disaster Database (n.d.) 2007 Disasters in numbers. Available online at: http://www. unisdr.org/eng/media-room/facts-sheets/2007-disasters-in-numbers-ISDR-CRED.pdf (17 November 2008).

Jain, V., Noponen, R. and Smith, B.M. (2003, May) 'Pediatric surgical emergencies in the setting of a natural disaster: experiences from the 2001 earthquake in Gujarat, India', Journal of Pediatric Surgery, Vol. 38, No. 5, pp.663-667.

Joshipura, M.K., Shah, H.S., Patel, P.R., Divatia, P.A. and Desai, P.M. (2003) 'Trauma care systems in India', Injury, International Journal of the Care of the Injured, Vol. 34, No. 9, pp.686-692.

Kaji, A.H., Koenig, K.L. and Lewis, R.J. (2007) 'Current hospital disaster preparedness', Journal of the American Medical Association, Vol. 298, No. 18, pp.2188-2190.

Kaur, J. (2006) 'Administrative issues involved in disaster management in India', International Review of Psychiatry, Vol. 18, No. 6, pp.553-557.

Kaushik, H.B., Dasgupta, K., Sahoo, D.R. and Kharel, G. (2006, August) 'Performance of structures during the Sikkim earthquake of 14 February 2006', Current Science, Vol. 91, No. 4, pp.449-455.

Knotts, K.E., Etengoff, S., Barber, K. and Golden, I.J. (2006, November-December) 'Casualty collection in mass-casualty incidents: a better method for finding proverbial needles in the haystack', Prehospital and Disaster Medicine, Vol. 21, No. 6, pp.459-464.

Mehta, S. (2006) 'Disaster and mass casualty management in a hospital: how well are we prepared', Journal of Postgraduate Medicine, Vol. 52, No. 2, pp.89-90.

Merin, O., Ash, N., Levy, G., Schwaber, M.J. and Kreiss, Y. (2010) 'The Israeli field hospital in Haiti-ethical dilemmas in early disaster response', The New England Journal of Medicine, Vol. 362, No. 11, pp.e38.

Merson, M.H., Black, R.E. and Mills, A.J. (Eds) (2006) International Public Health: Disease, Programs, Systems, and Policies, Jones and Bartlett Publishers, Boston, MA, USA.

Metri, B. (2006) 'Disaster mitigation framework for India using quality circle approach', Disaster Prevention and Management, Vol. 15, No. 4, pp.621-635.

Nanda, S.K. (2008) Safe Hospital Initiative in the Aftermath of the 2001 Earthquake in Gujarat (India), A Report of the Regional Consultation of SEAR Member Countries on Keeping Health Facilities Safe from Disasters, 15-17 April 2008, Regional Office for South-East Asia, World Health Organization, New Delhi, India.

Noji, E. (Ed.) (1997) The Public Health Consequences of Disasters, Oxford University Press, New York, USA.

Ofrin, R. and Salunke, S.R. (2006, December) 'Disaster preparedness in the South East Asia region', International Review of Psychiatry, Vol. 18, No. 6, pp.495-500.

Roy, N., Shah, H., Patel, V. and Coughlin, R.R. (2002) 'The Gujarat earthquake (2001) - a seismically unprepared area: community hospital medical response', Prehosptial and Disaster Medicine, Vol. 17, No. 4, pp.186-195.

Sabri, A.A. and Qayyum, M.A. (2006, September) 'Why medical students should be trained in disastser management: our experience of the Kashmir earthquake', Plos Medicine, Vol. 3, No. 9, pp.1452-1453.

Sharma, V., Tomar, R.S. and Ahola, N. (2008, May) 'Branding India for health and spiritual tourism: health, spiritual and heritage tourism', Proceedings of the Conference on Tourism in India-Challenges Ahead, 15-17 May, IIMK. 
S.M. Smith, J. Gorski and H.C. Vennelakanti

United Nations (2009a) 2008-2009 World disaster reduction campaign. Available online at: www.unisdr.org/wdrc-2008-2009

United Nations (2009b) Hospitals safe from disasters. Available online at: www.who.int/hac/ techguidance/safehospitals

USAID (2005) USAID India: Our Work-Strategic Objective 3-Disaster Management. Available online at: http://www.usaid.gov/in/our_work/strategy/strategy6.htm (accessed on 5 August 2008).

Wickramasinghe, K.K., Ishara, M.H., Liyanage, M.H., Karunathilake, I.M. and Samarasekera, D. (2007, September) 'Outcome-based approach in development of a disaster management course for healthcare workers', Annals Academy of Medicine, Vol. 36, No. 9, pp.765-769. 